\title{
Quick takes
}

\section{Larry Goodson}

These brief summaries highlight the key points and action steps in the feature articles in this issue of Strategy \& Leadership. Larry Goodson, an S\&L contributing editor, is a veteran strategy consultant based in St. Louis, Missouri. He is a Partner at LDGA Consulting, which offers Lean operations and strategy development services (Idgoodson@msn.com).

Gary Pisano: keeping the larger firm vibrant and innovative Leavy Brian
Can corporate giants learn to dance? This question reflects a long held view that established companies often seem to lose their capacity for innovation as they mature. Are mature firms then destined to fall prey to the marketplace's "winds of creative destruction" and eventually be upended by disruptive upstarts? Not so, according to Gary Pisano in his latest book, Creative Construction: The DNA of Sustained Innovation.

Strategy \& Leadership: Given the extensive literature on innovation, what prompted you to write your latest book?

Gary Pisano: First, a lot of what I was reading about innovation did not square with my consulting experience or with my academic research. There were just too many exceptions to the "law" that big companies can't do transformative innovation. Second, I wrote Creative Construction to serve as a comprehensive roadmap for companies that were trying to rejuvenate their innovative capacities.

$S \& L$ : Because of today's increasingly dynamic competitive environment you believe that the primary aim of corporate leadership should be to build the "creative constructive enterprise." What are the main challenges involved?

Pisano: There are three basic jobs in building a creative constructive enterprise. First, create the innovation strategy that sets out clear priorities around the types of innovation that are most important to pursue. Second, they need to design the systems that enable the company to search for, synthesize and select the innovation opportunities that align with their strategy. Third, they need to build the right culture.

$S \& L$ : When employing your innovation strategy framework, how should corporate leaders determine the optimal resource allocation balance in their innovation portfolios?

Pisano: There is no golden rule that applies to all companies. The right allocation depends on such factors as competitive dynamics, the evolution of customer preferences and technology cycles. So I recommend focusing on four critical questions in helping to shape this important choice: how fast is our core market capable of growing, what are the still unmet customer needs, how much potential does our existing technological paradigm still have for improvement and where can we create barriers to imitation?

S\&L: Finally, you see "creative constructive leadership" as a mindset that all aspiring leaders should look to cultivate regardless of current managerial level.

Pisano: Creative constructors are outward looking and are problemsolvers. They view innovation as the competitive weapon of choice. 
Opportunity-based growth management: enabling a companywide effort to proactively take advantage of new business prospects Vladyslav Biloshapka and Oleksiy Osiyevskyy
Corporate survival in today's market economy requires creative management of the growth imperative - find new revenue streams or fail. As a consequence, the effectiveness of a firm strategy is primarily determined by the quantity and quality of opportunities for revenue and profit growth. So, how can practicing managers bridge the gap between the strategizing process and emerging marketplace opportunity landscape? Our suggested solution is a systematic, company-wide growth management system that works in tandem with the strategizing process.

Opportunity-based growth management (OGM) system: the USATCO approach

A six-component approach understanding, scanning, articulating, testing, choosing, and organizing [USATCO] - is the foundation of the opportunity-based growth management (OGM) system. It is designed to enable management to address three critical goals in a systematic and cyclical process:

1. Identify and exploit emerging marketplace opportunities unoccupied niches, underserved customers, new technologies or processes before competitors.

2. Leverage information available across levels and departments of the company, particularly among front-line employees.

3. Assess the company's current business models and make necessary adjustments.

The opportunity-based growth management system is powered by six key activities:

1. Understanding. The first step for proactive opportunity-based growth management starts with obtaining a precise and detailed view of the factors that drive the current financial performance.
2. Scanning. The scanning process fosters a proactive search for growth opportunities for each of the drivers.

3. Articulating. Aggregation of individual managers' opportunity maps allows company-wide articulation of the growth strategy.

4. Testing. Before full commitment to each particular project within the firm-level growth strategy, its key underlying assumptions must be tested with the key customers and partners.

5. Choosing. At this stage strategists must make crucial choices by answering a practical question: what goals can be achieved given the firm's current human, financial and knowledge resources? Based on this assessment priority growth projects are determined and the firm decides which growth paths should be pursued and which should be left for a later stage or abandoned.

6. Organizing. At this last stage, the final plans - the list of growth projects aimed at exploiting particular market opportunities get translated into tasks and Key Performance Indicators for each manager and unit.

OGM: linking "strategy-as-learning" with "strategy-as-planning" paradigms

The OGM approach allows bridging the "strategy-as-learning" with "strategy-as-planning" paradigms, opening a pathway for proactive, intentional management of firm's growth by identifying and exploiting the marketplace opportunities. Embracing this paradigm leads to continuous evaluation and reevaluation of the objective customer value created by the company's business model. 
Sustaining open innovation through a "Center of Excellence"

Elizabeth E. Richard, Jeffrey R. Davis, Jin H. Paik, and Karim R. Lakhani

Getting to insight: the value and use of small data

Liam Fahey
Henry Chesbrough, author of several classic books on open innovation, defines it as "the use of purposive inflows and outflows of knowledge to accelerate internal innovation, and expand the markets for external use of innovation...." In the past 10 years, many organizations have adopted open innovation (OI).

While many OI pilot projects are successful, too often the efforts fizzle out after the initial burst of activity. Our experience in running hundreds of challenges seeking solutions to intractable problems in partnership with several research and development organizations leads us to recommend that organizations establish a Center of Excellence (COE) to promote and sustain a culture that effectively adopts $\mathrm{OI}$.

The experience of the Human Health and Performance Directorate (HH\&P) at NASA, which has also been reported in a Harvard Business School case, provides a successful example of moving from pilot challenges to establishing the Center of Excellence for Collaborative Innovation (CoECl) to sustain open innovation in seven years. After conducting a thorough retrospective analysis, we suggest a process for condensing the timeline to three years.

Organizations must build upon the initial success, plan for subsequent engagements, effectively recruit champions, develop training and communications outreach and address cultural barriers. The four phases of implementation of our open innovation program are learn, pilot, scale and sustain.

\section{Accelerating innovation}

Reduce the learning phase to six months. In each section of

Every organization can empathize with this senior executive's comment after a lengthy
"Accelerating innovation," we recommend conducting several learning activities in parallel. These include planning, creating a platform and collaborating internally.

Reduce the pilot phase to six months.

The pilot phase requires the organization to partner with one or more platforms to effectively run the challenges and champion the overall Ol effort. It is imperative that evaluation criteria and implementation strategies are outlined prior to the launch of a crowdsourcing contest and also that personnel are trained in all aspects of the process and, in particular, on how to write a good problem statement.

Reduce the scale phase to 18 months. Starting the acquisition process for longer-term platform contracts toward the end of the pilot phase will greatly reduce the time spent to scale OI capabilities across the organization.

Reduce the sustain phase to six months. Organizations should assess development or acquisition of a decision support tool and plan for testing and deployment to enhance Ol adoption and greatly accelerate this phase. Requiring the consideration of $\mathrm{OI}$ in performance plans or establishing the use of $\mathrm{OI}$ as policy may enable faster adoption across the organization. OI challenges hold the promise of faster execution, lower cost and higher success rates.

\section{Sustaining success}

We strongly recommend establishing a Center of Excellence to apply this methodology successfully.

PowerPoint presentation. "We seem to be data rich but severely insight deficient." 
While there are many reasons for the insight deficit, two seem especially prevalent and important:

- Little shared understanding as to what insight is and is not.

- A lack of an analysis roadmap designed specifically to help teams move from data to insight, especially in the case of small data.

To facilitate its use by strategists and marketers, we can define insight as, "New marketplace understanding that makes a difference." Its two practice components are:

- Crafting new understanding of change in and around the marketplace.

- Extracting implications of the new understanding for the organization's thinking, decision making and actions.

To qualify as an insight a new understanding should first undergo a detailed consideration of its implications.

Reassessing the value of small data

The insight potential of small data is typically ignored. Yet, time and again, small data proves to be the source of inferences that reveal a pathway to new marketplace understanding that may make a real difference to thinking, decision-making and action.

Search for small data opportunities

Once analysts accept the legitimacy of small data as a source of interesting inferences they typically discover small data insight opportunities in unexpected places.

\section{Structure the context}

Small data clues always exist within a specific context. The capacity to draw

M\&A deal-making: Disney, Marvel and the value of "hidden assets" Joseph Calandro, Jr. quality inferences depends upon understanding the context: what inferences can we draw - and about what - from the data?

The analyst or manager should pose two questions:

1. Is the context appropriate? For example, do genuine data source contradictions exist? Is there a real anomaly, outlier or dilemma present?

2. Have we documented the context? For example, have we detailed the cause-effect connections in causal difference? Have we detailed the differences in data conflicts?

\section{Drawing preliminary inferences}

The value of inferences in part lies in the fact that it is impossible to anticipate or predict what inferences will be drawn or to what they will pertain. Thus, what is inferred often is a surprise.

Does the new understanding make a difference?

Even though the new understanding based on small data may be only suggested or tentative and has not been fully vetted, it may still be highly valuable to ask, if it were genuine, what difference would it make to our thinking, decision making and action?

Small data opens unique avenues to insight

By paying careful attention to such small data opportunities, fully assessing their inferences and vetting them thoroughly, strategist and marketers can discover insights that Big Data cannot deliver.

$\$ 2$ billion that year alone. Super-hero themed movies also powered the entertainment industry in 2017 and 
2016. It might come as a surprise when people learn that the creator of many super-hero characters, Marvel Entertainment Group (Marvel), filed for bankruptcy in 1996.

The battle for control of Marvel that took place during the bankruptcy process was as entertaining as any super-hero comic book saga. Isaac Perlmutter, then the largest stockholder of Toy Biz, which had a minority interest in Marvel emerged as the owner for the sum of $\$ 238$ million.

Perlmutter and his team had a better understanding of the value of Marvel's portfolio of heroic characters and story-lines. In strategic terms, they also had an "information advantage" that facilitated their gaining control of Marvel and their realizing value as a result of that control over time. The value of Marvel made headlines on August 31, 2009, when Disney acquired it for $\$ 4$ billion.

\section{Hidden assets and value realization}

Disney's value realization strategy was based on aggressively investing in movies based on Marvel's portfolio of super-hero characters and, significantly, its decades-old comic book source material.

Disney's development of these movie themes resulted in the 2012 blockbuster movie The Avengers, as well as a number of other hits that, cumulatively, generated profits well in excess of the $\$ 4$ billion acquisition price-in fact, 3.3 times that price.

Agility, skills and cybersecurity: critical drivers of competitiveness in times of economic uncertainty

Anthony Marshall and Dave Zaharchuk

by combination of rapid technological change, political and social volatility and renewed protectionism, is
Some professional value investors have made fortunes hunting for hidden assets in the firms they invest in. But bargain hunters beware. What appears to be hidden assets today could turn out to be liabilities tomorrow. The risk of over bidding for hidden assets is particularly high in cases of hidden intangible assets, like those at Marvel.

\section{The search for hidden M\&A gold}

The M\&A market has become increasingly competitive over the years for a number of reasons, including increased participation by alternative investors and high-networth individuals. An information advantage that corporate strategists generally have over financiers is their more detailed understanding of the industries in which they work and the industries' dynamics.

One way to monetize such an advantage is, first, through the identification and strategic development of hidden assets that can be the basis for new business models. Second, strategists can take steps to mitigate the risk that hidden liabilities will cause value destruction.

The Disney acquisition of Marvel is a dramatic example of how strategic knowledge of hidden intangible assets can be used to win at dealmaking in a competitive marketplace.

economies on the risks and discontinuities they face. influencing corporate decisionmaking. The IBM Institute for Business Value (IBV) in collaboration with Oxford Economics surveyed more than 2,700 C-level executives across the 12 largest national
Key findings:

- 90 percent of executives cite skilled labor availability and quality as a critical factor for their organization when considering expansion into new markets. 
- 56 percent of executives say cyber threats are among the biggest strategic risks for their nation's economy in the next five years.

- 120 million workers in the world's 12 largest economies may need to be retrained/reskilled in the next three years as a result of intelligent/Al-enabled automation.

Forecast: lingering uncertainty with limited visibility

In late September 2018, the Organisation for Economic Cooperation and Development (OECD) published an interim economic outlook concluding that high levels of uncertainty are weighing negatively on global economic growth. To better gauge the path forward for policy makers and business and education leaders across major economies, IBM researchers asked the 2,700 C-level executives surveyed to share their insights into major risks, challenges and opportunities facing their nations today and in the future.

\section{Strategic opportunities}

Executive outlooks on the future are not all negative. When asked about the most important opportunities facing their nation's economy, global executives remain focused on global business integration and innovation - contrary to the forces of insularity and populism evident across many economies. More than half of all executives surveyed - 56 percent - believe business value can be increased by deeper collaboration with global partners. The strategic opportunity with the second highest number of percentage points is being a technology innovator. To accelerate toward higher growth and capitalize on strategic growth opportunities, nations and regions around the world need a skilled and talented workforce.

\section{Building a sustainable future}

Navigating this era of uncertainty will require collaboration and coordinated action across ecosystems including industry, education, public policy and economic development leaders. There are three primary focus areas that can enable nations and regions to mitigate risk and foster economic vitality:

- Build informed and agile strategies.

- Prioritize skills development.

- Bolster cybersecurity capabilities. 